\title{
PENANGKAPAN IKAN DI SUNGAI MARO, MERAUKE
}

\author{
Yayuk Sugianti" dan Hendra Satria') \\ 1) Peneliti pada Loka Riset Pemacuan Stok Ikan, Jatiluhur-Purwakarta \\ Teregristrasi I tanggal: 28 Pebruari 2007; Diterima setelah perbaikan tanggal: 23 April 2007; \\ Disetujui terbit tanggal: 30 Mei 2007
}

\begin{abstract}
ABSTRAK
Sungai Maro berada di Wilayah administrasi Kabupaten Merauke Propinsi Papua berfungsi untuk kegiatan transportasi dan perikanan tangkap sehingga merupakan salah satu sungai di Kabupaten Merauke yang memberi kontribusi perikanan yang besar antara lain merupakan daerah penangkapan ikan arwana Irian (Sclerophages jardini). Penelitian bertujuan untuk mengetahui jenis ikan, alat tangkap, status, dan aspek sosial ekonomi sebagai informasi yang berguna untuk mendukung konstribusi dalam pengelolaan perikanan di Sungai Maro, Merauke. Penelitian dilakukan dengan metode survei dan wawancara pada bulan April, Juli, September, dan Nopember 2006. Lokasi penelitian ditentukan berdasarkan pada daerah yang merupakan sentra ikan arwana yaitu Toray, Bupul, Kweel, Barkey, Kaliwango (Distrik Sota), dan Tanas (Distrik Elikobel). Hasil penelitian menunjukkan bahwa hasil tangkapan terdapat 19 jenis ikan dengan 8 macam alat tangkap. Penangkapan ikan di Sungai Maro belum optimal karena nelayan banyak menggunakan alat tangkap tradisional.
\end{abstract}

KATAKUNCl: jenis-jenis ikan, alat tangkap, aspek sosial ekonomi masyarakat, status perikanan

\section{PENDAHULUAN}

Kabupaten Merauke Propinsi Papua merupakan salah satu kabupaten di Indonesia yang berbatasan langsung dengan negara tetangga yaitu Papua Nugini (darat) dan Australia (laut). Terletak pada posisi geografi $137^{\circ} 30^{\prime}-141^{\circ} 00^{\prime}$ BT dan $5^{\circ} 00^{\prime}-9^{\circ} 13^{\prime}$ LS memiliki luas wilayah $44.075 \mathrm{~km}^{2}$. Sebagian besar $(60 \%)$ daerah terdiri atas perairan rawa-rawa dengan 11 sungai besar dan anak-anak sungai. Kabupaten Merauke dapat memberikan devisa yang cukup besar untuk pendapatan asli daerah, terutama dari ikan arwana Irian (Scleropages jardini). Sungai Maro yang berada di wilayah administrasi Kabupaten Merauke, dengan panjang sungai $207 \mathrm{~km}$ dan lebar 48 sampai dengan $900 \mathrm{~m}$ merupakan salah satu daerah penangkapan ikan arwana Irian. Sungai Maro juga dimanfaatkan untuk kegiatan transportasi dan perikanan tangkap sehingga menjadi salah satu sungai di Kabupaten Merauke yang memberi kontribusi perikanan yang besar. Selain itu, ikan arwana perak banyak juga terdapat ikan-ikan konsumsi lain. Namun, potensi perikanan di Sungai Maro ini belum dimanfaatkan secara optimal, selain karena lokasi yang agak sulit untuk dijangkau dari arah kota, nelayan setempat juga belum dapat mengembangkan potensi perikanan yang ada. Alat tangkap yang digunakan untuk menangkap ikan di Sungai Maro pun terbilang tradisional.

Melihat kondisi tersebut perlu dilakukan penelitian untuk memberikan informasi yang bermanfaat sebagai kontribusi dalam pengelolaan perikanan di Sungai Maro, Merauke.

\section{METODE PENELITIAN}

Penelitian dilakukan pada bulan April, Juli, September, dan Nopember 2006 dengan metode survei dan wawancara. Lokasi penelitian ditentukan berdasarkan pada daerah yang merupakan sentra ikan arwana yaitu Toray, Bupul, Kweel, Barkey, Kaliwango (Distrik Sota), dan Tanas (Distrik Elikobel) (Tabel 1). Hasil pengamatan selanjutnya dianalisis secara deskriptif.

\section{JENIS ALAT TANGKAP IKAN DAN CARA PENGOPERASIAN}

Tahun 2004 jumlah rumah tangga perikanan (perikanan darat dan laut) di wilayah Kabupaten Merauke mencapai 4.98 dengan jumlah tertinggi di Distrik Merauke mencapai 855 rumah tangga perikanan atau sektiar $17,162 \%$ dari total rumah tangga perikanan. Distrik Merauke sendiri berbatasan langsung dengan Laut Arafura, masyarakat pesisir sebagian besar bermata pencaharian sebagai nelayan. Rumah tangga perikanan di Kabupaten Merauke sebagian besar bergerak pada kegiatan penangkapan ikan (nelayan) (Sumber: Dinas Perikanan dan Kelautan Kabupaten Merauke, 2005a). Alat tangkap yang digunakan nelayan belum bervariasi seperti terlihat pada Tabel 2 . 
Tabel 1. Deskripsi stasiun pengamatan di Sungai Maro

\begin{tabular}{|c|c|c|}
\hline Stasiun penelitian & Posisi geografi & Deskripsi lokasi \\
\hline Toray & $\begin{array}{l}S=08^{\circ} 00^{\prime} 29.2^{\prime \prime} \\
E=140^{\circ} 58^{\prime} 36.4^{\prime \prime}\end{array}$ & $\begin{array}{l}\text { Daerah rawa dengan tumbuhan air yang subur dan arus } \\
\text { agak deras. Kedalaman mencapai } 6 \mathrm{~m}\end{array}$ \\
\hline Bupul & $\begin{array}{l}S=07^{\circ} 32^{\prime} 59.7^{\prime \prime} \\
E=140^{\circ} 51^{\prime} 00.1^{\prime \prime}\end{array}$ & Warna air coklat. Sekitar hutan \\
\hline Kweel & $\begin{array}{l}S=07^{\circ} 43^{\prime} 48.3^{\prime \prime} \\
E=140^{\circ} 53^{\prime} 02.1^{\prime \prime}\end{array}$ & Dekat dengan permukinan \\
\hline Tanas & $\begin{array}{l}S=07^{\circ} 35^{\prime} 48.1 " \\
E=140^{\circ} 49^{\prime} 55.8^{\prime \prime}\end{array}$ & $\begin{array}{l}\text { Dekat dengan permukiman. Sungai lb yang merupakan } \\
\text { anak Sungai Maro. }\end{array}$ \\
\hline Barkey & $\begin{array}{l}S=07^{\circ} 51^{\prime} 24.7^{\prime \prime} \\
E=140^{\circ} 58^{\prime} 10.6^{\prime \prime}\end{array}$ & $\begin{array}{l}\text { Warna air coklat, lingkungan sekitar merupakan hutan } \\
\text { gundul. }\end{array}$ \\
\hline Kaliwango & $\begin{array}{l}S=08^{\circ} 02^{\prime} 29.6^{\prime \prime} \\
E=140^{\circ} 58^{\prime} 27.0^{\prime \prime}\end{array}$ & $\begin{array}{l}\text { Lingkungan sekitar berupa hutan, air berwarna coklat, } \\
\text { tidak terdapat pemukiman penduduk. }\end{array}$ \\
\hline
\end{tabular}

Tabel 2. Jenis dan jumlah alat tangkap di Kabupaten Merauke

\begin{tabular}{ccccccccc}
\hline No. & $\begin{array}{c}\text { Distrik/alat } \\
\text { tangkap }\end{array}$ & $\begin{array}{c}\text { Jaring } \\
\text { insang } \\
\text { hanyut }\end{array}$ & $\begin{array}{c}\text { Jaring } \\
\text { insang } \\
\text { tetap }\end{array}$ & Serok & $\begin{array}{c}\text { Rawai } \\
\text { hanyut }\end{array}$ & Pancing & Bubu & Jala \\
\hline 1 & Merauke & 2.810 & 6.710 & 405 & 185 & 639 & 33 & 38 \\
2 & Semangga & 657 & 653 & 367 & - & 162 & - & 68 \\
3 & Tanah & 4 & 545 & 53 & - & 35 & - & 11 \\
& Miring & & & & & & & \\
4 & Kurik & 450 & 1.003 & 17 & - & 105 & - & 5 \\
5 & Jagebob & - & 762 & 73 & - & 58 & 13 & 51 \\
6 & Okaba & 916 & 201 & 63 & - & 102 & - & - \\
7 & Sota & - & 436 & 237 & - & 96 & 43 & 17 \\
8 & Elikobel & 21 & 327 & - & - & 170 & 22 & 163 \\
9 & Ulilin & 15 & 327 & - & - & 23 & 13 & 7 \\
10 & Muting & 75 & 109 & - & - & 165 & 18 & 35 \\
11 & Kimaam & 1.478 & 2.178 & 2.011 & - & 37 & 89 & 117 \\
\hline
\end{tabular}

Sumber: Dinas Perikanan dan Kelautan Kabupaten Merauke (2005b)

Nelayan di sekitar Sungai Maro sangat bergantung pada hasil tangkapan ikan, namun hasil belum optimal dikarenakan menggunakan alat tangkap tradisional dan bersifat pasif. Alat tangkap perikanan khusus yang digunakan di perairan Sungai Maro adalah gill net, pancing, rawai, jala, bubu, tombak atau kalawai, kaboti (sejenis bubu), dan panah (Gambar 1).
Alat tangkap panah digunakan nelayan di Sungai Maro untuk menangkap ikan belanak, kakap, dan gastor. Digunakan pada saat siang, sore, atau malam di mana air tinggi ataupun surut. Panjang total panah yaitu $121 \mathrm{~cm}$, dengan panjang total mata panah berkisar antara 13 sampai dengan $26 \mathrm{~cm}$, sedangkan panjang total bambu berkisar antara 91 sampai dengan $108 \mathrm{~cm}$. Busur yang terbuat dari bambu panjang mencapai $197 \mathrm{~cm}$ dan panjang tali $184 \mathrm{~cm}$. 

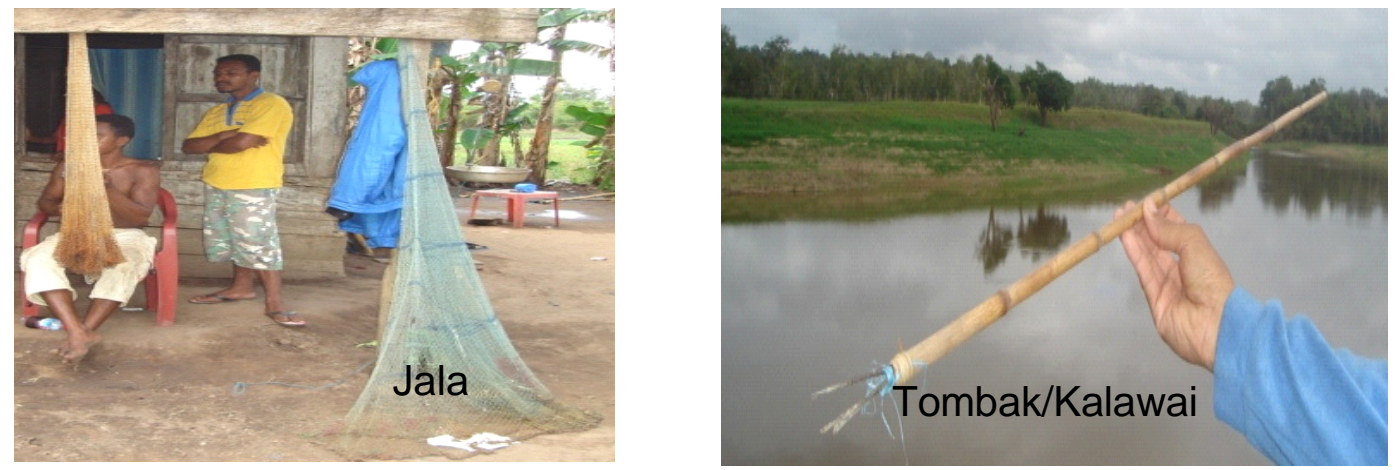

Gambar 1. Berbagai alat tangkap tradisional di Sungai Maro.

Gill net atau jaring insang terdiri atas 2 jenis yaitu gill net apung dan gill net dasar, gill net apung dipasang di permukaan ditujukan untuk menangkap ikan-ikan yang bergerombol. Tetapi tidak demikian hal dengan gill net dasar, ikan-ikan yang terjaring di dasar jenis bermacam-macam (Widodo, 2006). Gill net di Sungai Maro digunakan untuk menangkap ikan arwana Irian dan kakap rawa. Untuk menangkap jenis ikan arwana para nelayan menggunakan gill net dengan mata jala yang besar yaitu 3,5 sampai dengan 5 inci. Gill net tersebut terbuat dari nilon yang tebal dengan jaring dipasang pada sore hari dan diangkat setelah diperkirakan ada ikan arwana yang terjerat di jaring (sekitar 0,5 sampai dengan 1 jam) melingkar

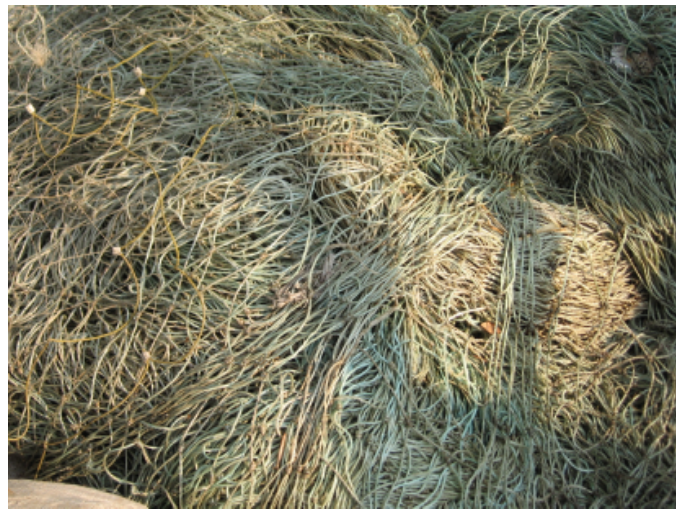

Gambar 2a. Gill net dengan bahan benang nimo.

Gill net dipasang membelah aliran sungai dengan mengikatkan ke-2 ujung di tanaman air yang banyak terdapat di pinggir sungai. Alat tangkap yang digunakan nelayan di Sungai Maro mempunyai panjang mencapai $60 \mathrm{~m}$ dengan kedalaman $6 \mathrm{~m}$. Alat ini dipasang 5 hari dalam seminggu lalu diangkat untuk dibersihkan dan dipasang kembali, alat ini bertahan (berbentuk U) (Gambar 2b). Cara pengoperasian yaitu ikan arwana yang bersembunyi di rawa-rawa digiring keluar rawa agar masuk ke gill net dengan cara memukul-mukul air sekitar rawa dengan tongkat. Setelah ikan tersangkut gill net akan terkejut dan memuntahkan anakan. Pada saat itu anakan ditangkap dengan menggunakan seser.

Selain untuk ikan arwana, gill net juga digunakan untuk menangkap ikan kakap rawa. Penangkapan ikan kakap rawa menggunakan gill net dengan ukuran mata jaring 7 sampai dengan 10 inci, dengan bahan dari nilon dan benang yang menurut masyarakat setempat disebut benang nimo (Gambar 2a).

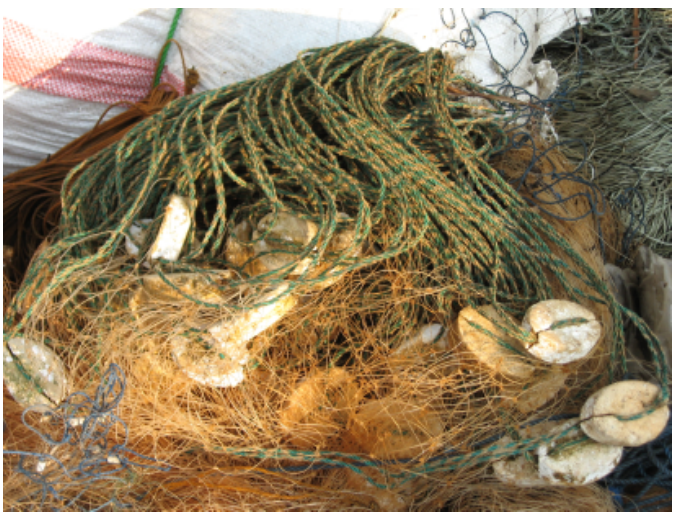

Gambar 2b. Gill net dengan bahan nilon.

sampai dengan 6 tahun. Harga alat yang terbuat dari nilon adalah Rp.400.000, sedangkan dari benang nimo harga Rp.150.000.

Alat tangkap pancing juga banyak digunakan di Sungai Maro, pancing yang digunakan sangat sederhana terdiri atas bambu atau botol sebagai joran, 
benang nilon, dan kail. Kegiatan memancing ini dilakukan sore hari oleh ibu-ibu dan anak-anak. Umpan yang pada umumnya digunakan adalah ikanikan kecil. Ikan yang pada umumnya tertangkap antara lain ikan mata bulan (Thryssa scratcleyi) dan duri (Arius latirostris). Selain itu, pancing juga dapat digunakan untuk menangkap udang galah. Umpan yang digunakan adalah terasi. Penangkapan udang galah mulai petang (pukul 18.00) sampai dengan pagi

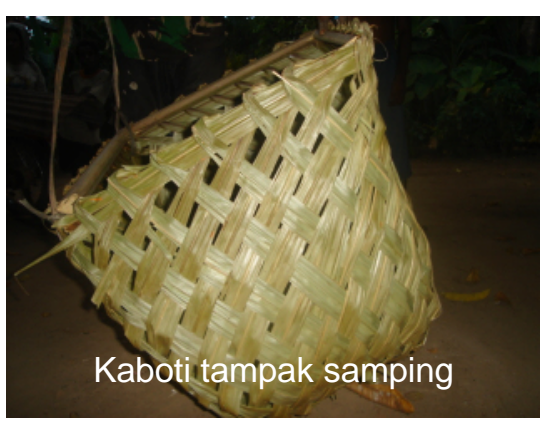

Gambar 3.

\section{JENIS-JENIS IKAN YANG TERTANGKAP}

Selama pengamatan, ikan yang tertangkap di Sungai Maro berjumlah 19 jenis ikan yaitu arwana Irian (Sclerophages jardinii), kurikil atau kakap batu (Datnicides sp.), tulang (Megalops sp.), tung (Apogon sp.), kaca (Parambasis sp.), saku (Stronggylura kreffti), sembilang (Toundanus sp.), sumpit (Toxotes sp.), mujair (Oreochromis mossambicus), gastor (Channa sp.), duri (Arius latirostris), kakap kembang (Glossamia apton), mata bulan (Thryssa scratcleyi), nila (Oreochromis niloticus), udang putih (Macrobranchiumsp.), bulanak (Valamugilsp.), kakap rawa (Lates carcarifer), gete-gete besar (Apogon wichmani), dan cherax biru (Cherax albertisi).

Khusus untuk menangkap ikan arwana Irian, hasil dari wawancara dengan nelayan di wilayah Distrik Sota, Desa Erambo Kampung Toray, diperoleh informasi bahwa musim pemijahan ikan arwana pada bulan-bulan Oktober, Nopember, dan terakhir pada bulan Desember atau awal musim hujan. Produksi yang dihasilkan di wilayah Kabupaten Merauke dapat mencapai anakan ikan arwana 600.000 sampai dengan 800.000 ekor. Jaring insang dipasang pada daerah-daerah tertentu, yang diperkirakan sebagai tempat pemijahan dan perlindungan ikan arwana untuk membesarkan anak-anak, dipasang pada daerah rawa-rawa yang terlindung dari arus air dan banyak tumbuhan air. Anakan ikan arwana ini, diperoleh dari hari (pukul 04.00) tergantung tingkat kekuatan nelayan.

Selain itu, ada juga alat tangkap kaboti di wilayah Kweel yang terbuat dari daun sagu menyerupai bubu (Gambar 3). Alat tangkap ini digunakan untuk menangkap berbagai jenis ikan, dipasang saat petang dengan diberi rumput-rumput sebagai sarangan yang menyerupai habitat tempat berlindung ikan dan diangkat pagi hari.

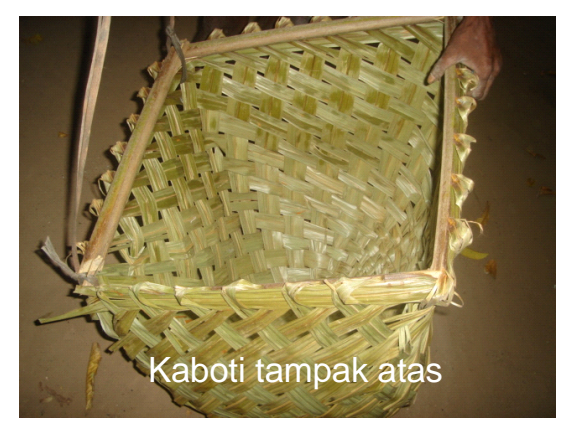

Alat tangkap kaboti.

induk ikan arwana yang disimpan dalam mulut. Ikan arwana yang tertangkap, dengan segera dibuka mulut dan dikeluarkan anak, kemudian ditampung dengan jaring halus atau ember yang dipersiapkan.

\section{SOSIAL EKONOMI MASYARAKAT}

Masyarakat sekitar lokasi penelitian hidup dengan serba keterbatasan. Fasilitas penerangan listrik hanya ada di Toray dengan jam nyala mulai pukul 18.00 sampai dengan 00.00 malam. Sedangkan di Bupul, Tanas, Kweel belum tersentuh fasilitas listrik. Fasilitas pendidikan yang ada adalah sekolah dasar, sedangkan sekolah menengah pertama hanya ada di ibukota kecamatan (distrik). Fasilitas jalan utama jalur Merauke sampai dengan Asmat dibangun jalan aspal tetapi menuju lokasi penelitian jalan tanah. Rumah penduduk terbuat dari papan beratap seng. Alat transportasi dari Kota Merauke menuju lokasi penelitian adalah truk dan mobil garda 2. Fasilitas pasar belum ada, pembeli ikan hasil tangkapan datang langsung ke nelayan. Harga-harga kebutuhan pokok sehari-hari relatif mahal karena jalur transportasi yang sulit. Nelayan di sekitar Sungai Maro sangat bergantung pada hasil tangkapan ikan belum berpikir untuk pengembangan budi daya ikan dan penangkaran. Hal ini, kemungkinan berpangaruh terhadap tingkat kesejahteraan masyarakat nelayan yang rendah. Masyarakat Bupul terdiri atas 3 
masyarakat lokal dan 9 masyarakat transmigrasi. Masyarakat lokal bermata pencaharian sebagai ramu (mencari sumber pangan di hutan, sungai, dan tidak mempunyai pekerjaan tetap) sedangkan masyarakat transmigran bermata pencaharian sebagai petani.

Pada saat penelitian, hasil tangkapan yang melimpah adalah udang putih. Hasil tangkapan udang putih dijual ke tengkulak yang datang ke desa-desa. Berdasarkan pada hasil wawancara dengan nelayan setempat, harga udang putih di Toray Rp.10.000,- per kg, di Kweel mencapai Rp.15.000,- per kg, dan di Tanas Rp.1.000,- per ekor udang besar. Hasil tangkapan ikan pada umumnya untuk konsumsi sendiri dan pakan ternak babi dan anjing. Di Tanas ditemukan pula udang batu atau cherax (Cherax albertisii) yang kurang laku di pasaran yaitu sekitar 7.000,-per ekor. Di Daerah Toray ditemukan juga ikan kakap rawa yang panjang mencapai $89 \mathrm{~cm}$ dengan dihargai Rp.20.000,- sampai dengan 30.000 per ekor; arwana yang mati akibat masuk jaring nelayan dihargai Rp.15.000,-, satu ikat ikan kaca dan ikan berukuran sedang (3 ekor) dihargai Rp.10.000,- sampai dengan $15.000,-$. Nelayan ini menjual hasil tangkapan di pinggir jalan dan dibeli oleh penumpang maupun sopir truk atau angkutan lain yang melewati ruas jalan tersebut. Kegiatan menjual ikan di pinggir jalan hanya dilakukan saat musim kemarau sebab ikan lebih tahan lama dan tidak cepat busuk. Harga anakan ikan arwana pada minggu pertama musim pemijahan dapat mencapai Rp.15.000,- per ekor tetapi akan terus menurun, pernah mencapai harga terendah Rp.2.500,per ekor pada puncak musim pemijahan. Penurunan harga ini karena hasil panen ikan melimpah dan banyak stok ikan di pengumpul.

\section{KESIMPULAN}

Penangkapan ikan di Sungai Maro saat ini belum optimal karena nelayan banyak menggunakan alat tangkap tradisional. Selain itu, masyarakat Sungai Maro melakukan kegiatan menangkap ikan hanya untuk memenuhi kebutuhan sehari-hari tanpa berpikir untuk pengembangan budi daya ikan dan penangkaran. Hal ini, berpengaruh sekali terhadap tingkat kesejahteraan masyarakat nelayan. Untuk itu perlu ada bantuan atau kerja sama dari pihak yang terkait seperti Dinas Perikanan setempat agar dapat memberikan masukan dan penyuluhan pada masyarakat bagaimana cara pemanfaatan sumber daya perikanan yang berlimpah di Sungai Maro.

\section{PERSANTUNAN}

Hasil dari kegiatan riset pemacuan stok ikan arwana di Sungai Maro T.A. 2006 di Loka Riset Pemacuan Stok Ikan

\section{DAFTAR PUSTAKA}

Dinas Perikanan dan Kelautan Kabupaten Merauke. 2005a. Laporan tahunan 2004.

Dinas Perikanan dan Kelautan Kabupaten Merauke. 2005b. Database Perikanan Kabupaten Merauke tahun 2004.

Widodo, J. \& Suadi. 2006. Pengelolaan sumber daya perikanan laut. Gadjah Mada University Press. 252 hal. 